\title{
Effectiveness of Progressive Muscle Relaxation in Reducing Depression, Anxiety and Stress among Haemodialysis Patients attending a Public Hospital at Central Java Indonesia.
}

\author{
Hudiyawati $D^{a}$, Muhlisin $A^{a}$, Normala Ibrahim ${ }^{b}$ \\ aUniversitas Muhammadiyah Surakarta \\ buniversiti Putra Malaysia
}

\section{ABSTRACT}

The increasing trend of Chronic Kidney Disease (CKD) prevalence in Indonesia is a public health concern as it increases mortality, morbidity and burden of disease that has great implication on the health economic. In addition, CKD patients who are more likely to undergo hemodialysis is commonly associated with psychological problems such as depression, anxiety and stress and these have added more to the disease burden. Immediate measures such as progressive muscle relaxation (PMR) to reduce the psychological symptoms is of great importance before the symptoms progress into psychiatric disorders. The study was aimed to evaluate the effectiveness of PMR in reducing symptoms of depression, anxiety and stress among patients undergoing hemodialysis. It was a quasi-experimental, pretest-posttest control study that recruited 60 eligible respondents who underwent hemodialysis and was randomly allocated into intervention and waitlist control groups. Respondents in the intervention group performed PMR twice a day for two weeks. Mean scores of depression, anxiety and stress of respondents were examined before and after intervention using Depression, Anxiety and Stress Scale-21 questionnaire (DASS-21). Results showed that mean scores of depression, anxiety and stress differed significantly before and after intervention between groups and within the intervention group $(p<0.05)$. PMR was effective to reduce the psychological symptoms among patients underwent hemodialysis. This highlight the importance to screen psychological symptoms among those patients and PMR should be taught to them as one of the stress-reducing measures.

KEYWORDS: hemodialysis, progressive muscle relaxation (PMR), depression, anxiety, stress

\section{INTRODUCTION}

Chronic Kidney Disease (CKD) is determined by decreased or failure of kidney function. ${ }^{1}$ CKD is recognised as a global health concern due to the global prevalence of CKD rose up significantly. ${ }^{2}$ CKD patient in USA has increased annually, from 34.500 to 80.000 people within five years (2002-2007), and in 2010 it has escalated further up to 2 millions. The Research of Global Burden of Disease in 2010 said that CKD was the 27th worldwide leading dead in 1990 and has elevated to 18th position in $2010 .^{3}$ The number of incidence of end-stage renal disease

Corresponding Author:

Dian Hudiyawati

Jl. Jendral Ahmad Yani Pabelan

Kartasura-Surakarta,

Central Java 57102, Indonesia

No Tel : +6285697521219

Email : dian.hudiyawati@ums.ac.id
(ESRD) in Indonesia was increasing from year 2002 to 2006, by 10.2 and 23.4 , respectively. ${ }^{4}$

CKD is a global healthcare burden in Indonesia as a developing country, because it has a high economic cost in health management. ${ }^{4,5}$ Most of them require complex treatment including kidney replacement therapy such as continuous ambulatory peritoneal dialysis (CAPD), hemodialysis or kidney transplantation to support their life. ${ }^{5}$ Hemodyalisis is the most common treatment used in Indonesia. ${ }^{6}$

The presence of concurrent psychological problems in CKD is common and patients who undergo long-term hemodialysis have been found to experience psychological symptoms, such as depression and anxiety. ${ }^{7,8} \mathrm{Ku}$, et al. reported that $47 \%$ of hemodialysis patients had symptoms of depression while other studies also found that the prevalence of patients underwent hemodialysis who 
experienced depression was significantly high. ${ }^{9,10}$ It was reported that psychological distress has a negative effect on prognosis of the disease, including morbidity, mortality and non-adherence to the therapy. ${ }^{11-13}$

Progressive muscles relaxation (PMR) has shown significant benefit in reducing symptoms of depression, anxiety and stress as it alternately tenses and relaxes group of muscles in sequence. It assists the patients to calm their mind and focuses attention on the different feelings experienced when the muscles relax and tense. ${ }^{14}$

One previous study has reported that PMR helped to reduce depression. ${ }^{15}$ However, PMR has received less attention from health care provider although it is easily learned and performed by patients to overcome the psychological symptoms with less significant side effects. ${ }^{16}$ Many studies have emphasized the benefits of PMR in other than patients undergoing hemodialysis ${ }^{17}$ such as patients with hysterectomy ${ }^{18}$, cancer $^{19}$, primigravida women ${ }^{20}$ and cardiac chateterization. ${ }^{21}$ In the light of this, the objective of this study was to evaluate the effectiveness of PMR in reducing depression, anxiety and stress among hemodialysis patients.

\section{MATERIALS AND METHODS}

In this quasi-experimental, pre post-test control group study, sixty (60) eligible respondents from a hemodialysis unit in Sukoharjo Hospital, Central Java Indonesia were randomly allocated into intervention and control groups. The inclusion criteria were respondents with renal failure who underwent hemodialysis in the last 6 months, who were without hearing loss and consented to the study. The exclusion criteria were hemodialysis patients with neuromuscular diseases, hemodynamically unstable, those receiving psychotropic medications and those with diabetes mellitus and complications of cardiovascular diseases.

The estimated sample size of 60 respondents was based on a formula of two independent mean groups and parameters used were from Essa, et al. ${ }^{18}$ Thirty (30) respondents were allocated into the intervention and wait-list control groups. Those in the intervention groups received education on progressive muscle relaxation (PMR) from one of the researchers who were formally trained in PMR. The respondents were given instructions on steps of performing PMR using audio medium while those in the wait-list control groups only received the intervention after completion of the study.

\section{Intervention}

The respondents in the intervention group were instructed to perform PMR twice a day for 15 minutes during each session in the morning and evening every day for 2 weeks. Family members were engaged by the researchers to monitor adherence to PMR. In order to ensure that respondents performed PMR correctly, the researcher demonstrated the PMR procedures to the respondents and they were required to repeat the process until they performed it correctly. PMR procedure began with learning the correct breathing technique, alternate tensing and relaxing of the twelve $^{12}$ muscle groups and their combination procedure. Following 2 weeks of completing PMR, respondents in the intervention and control groups were re-evaluated on their depression, anxiety and stress level using the same set of questionnaire of DASS 21.

\section{Instrument for outcome measure}

All respondents from the intervention and control groups were assessed for their depression, anxiety and stress level using a set of pre-tested, self-administered and validated questionnaire ie Depression, Anxiety, Stress Scale 21 (DASS 21) in Indonesian language as a baseline measure prior to the implementation of the intervention and post intervention. DASS-21 has 3 domains which measures level of depression, anxiety and stress and each domain has 7 items that reflects symptoms related to those 3 psychological measures. The total score for each domain was used in the study with high score indicates high severity of the psychological symptoms. DASS-21 has good validity and internal consistency across studies in Indonesia and the overall Cronbach's alpha of DASS-21 in the present study was 0.82 .

\section{Ethics consideration}

The study was granted approval from the hospital ethics committee and all respondents were given informed consent and signed it prior to study recruitment. The respondents from the wait-list 
group were given an option to undergo the training of PMR procedure after the study completed. The respondents were also ensured that confidentiality was maintained throughout the study period.

\section{Statistical Analysis}

Data were analyzed using SPSS version 20 (citation). Frequency, percentage, mean and standard deviation were used in the descriptive analysis. Chi square test was used to compare the demographic variables between intervention and control groups. Independent t-test was used to compare the mean depression, anxiety and stress scores between groups, while paired t-test was used to evaluate the effectiveness of PMR on depression, stress and anxiety scores after intervention. The significance level was set at $0.05(\mathrm{P}<0.05)$.

\section{RESULTS}

A total of 60 respondents were included in the study and the mean age of the respondents was 54.2 years old. Of the 60 respondents, $63 \%$ were men and majority was in the age group of 41-60 years old
(72\%). Baseline comparison of socio-demographic characteristics between intervention and control groups is shown in Table 1. There was no significant difference between both groups in regards to demographic characteristics $(p>0.05)$.

Table 2 shows the comparison of mean scores of depression, anxiety and stress between intervention and control groups at baseline (pre test) and after intervention (post test). There was no significant difference in mean scores of depression $(p=0.691)$, anxiety $(p=0.743)$ and stress $(p=0.546)$ between intervention and control groups at baseline. Meanwhile, the mean scores of depression $(p=0.001)$, anxiety $(p=0.001)$ and stress $(p=0.001)$ between both groups differ significantly after intervention.

Comparison within groups shows that mean scores of depression $(p=0.001)$, anxiety $(p=0.001)$ and stress $(p=0.001)$ differ significantly before and after intervention in the intervention group. However there is no significant difference found in mean scores of depression $(p=0.530)$, anxiety $(p=0.601)$ and stress $(p=0.672)$ before and after intervention in the control group.

Table 1. Baseline comparsion of socio demographic characteristics between intervention and control groups

\begin{tabular}{lccccc}
\hline Variable & \multicolumn{2}{c}{ Intervention group } & Control group & P value* \\
\cline { 2 - 4 } & $(\mathrm{N}=30)$ & $\%$ & $(\mathrm{~N}=30)$ & $\%$ & \\
\hline
\end{tabular}

Age (years old)

\begin{tabular}{|c|c|c|c|c|c|}
\hline a. $20-40$ & 5 & 16.7 & 3 & 10 & 0.178 \\
\hline b. $41-60$ & 20 & 66.7 & 23 & 76.7 & \\
\hline c. Above 60 & 5 & 16.7 & 4 & 13.3 & \\
\hline \multicolumn{6}{|l|}{ Gender } \\
\hline a. Men & 18 & 60 & 20 & 66.7 & 0.744 \\
\hline b. Women & 12 & 40 & 10 & 33.3 & \\
\hline \multicolumn{6}{|l|}{ Employment status } \\
\hline a. Housewife & 6 & 20 & 7 & 23.3 & 0.87 \\
\hline b. Government Employee & 8 & 26.7 & 6 & 20 & \\
\hline c. Private Employee & 10 & 33.3 & 11 & 36.7 & \\
\hline d. Self-employed & 6 & 20 & 6 & 20 & \\
\hline
\end{tabular}

Education level

\begin{tabular}{|c|c|c|c|c|c|}
\hline a. Grade School & 7 & 23.3 & 6 & 20.0 & 0.912 \\
\hline b. Junior High School & 7 & 23.3 & 9 & 30.0 & \\
\hline c. High School & 8 & 26.7 & 6 & 20.0 & \\
\hline d. Scholar & 8 & 26.7 & 9 & 30.0 & \\
\hline \multicolumn{6}{|l|}{ Duration of haemodialysis } \\
\hline a. 4-5 months & 17 & 56.7 & 15 & 50.0 & 0.625 \\
\hline b. 2-3 months & 7 & 23.3 & 8 & 26.7 & \\
\hline c. below 2 months & 6 & 20.0 & 7 & 23.3 & \\
\hline
\end{tabular}

(*Significant level $p<0.05)$ 
Table 2. Comparison of total mean scores of depression, anxiety and stress between intervention and control groups

\begin{tabular}{llll}
\hline Variables & $\begin{array}{l}\text { intervention group } \\
(\mathrm{n}=30)\end{array}$ & control group $(\mathrm{n}=30)$ & p value* \\
\cline { 2 - 3 } & mean $\pm \mathrm{SD}$ & $\mathrm{mean} \pm \mathrm{SD}$ & $0.691^{\mathrm{a}}$ \\
\hline $\begin{array}{l}\text { Depression } \\
\text { Pre test }\end{array}$ & $7.85 \pm 1.78$ & $8.01 \pm 2.02$ & $0.001^{\mathrm{a}}$ \\
Post test & $4.03 \pm 1.40$ & $7.91 \pm 1.93$ & \\
Anxiety & & & $0.743^{\mathrm{a}}$ \\
Pre test & $12.32 \pm 2.01$ & $11.73 \pm 2.17$ & $0.001^{\mathrm{a}}$ \\
Post test & $6.23 \pm 1.30$ & $11.02 \pm 1.67$ & \\
Stress & $15.65 \pm 3.23$ & $15.20 \pm 3.45$ & $0.546^{\mathrm{a}}$ \\
Pre test & $7.05 \pm 2.94$ & $14.93 \pm 3.14$ & $0.001^{\mathrm{a}}$ \\
Post test & & &
\end{tabular}

(*Significant level $p<0.05)$

\section{DISCUSSION}

In general, the present study found that more than half of the patients who underwent hemodialysis in the center were men. However, this finding is not consistent with the distribution of gender in CKD patients in Indonesia. Prodjosudjadi, et al. found that the prevalence of CKD is higher in women $(64 \%)$ than in men $(36 \%)$ which the result was repeated in the study conducted by Hill (2016) that states CKD is more prevalent in women than in men. ${ }^{4}$

Although CKD is more prevalent in women than in men, previous studies showed the progression of the disease to CKD seemed to be more rapid in men as compared to women. ${ }^{22,23}$ Hence the number of men undergo heamodialysis is significantly larger than in women. This is possibly due to men having higher concentration of serum creatinine which was determined by their muscle mass. ${ }^{22}$ In addition, Carrero found that CKD patients with non diabetic complication experienced damage of renal function much slower in female than male, especially in female with moderate age group or premenopausal stage. ${ }^{24}$ Haroun et al. also found there was a risk association between smoking and CKD progression ${ }^{25}$ in which smoking was reported more prevalent in Indonesian men than women. ${ }^{4}$ In addition to smoking, hypertensive status which is more likely related to men is other important factor that is significantly associated with CKD. ${ }^{25,26}$

This study found that the majority of the patients who underwent hemodialysis was in the age group of 41-60 years old (72\%). This finding concurs with the previous study from Prodjosudjadi et.al, which found that patients with CKD was more prevalent in the age group of $40-59$ years old $(46.7 \%)^{4}$. This finding also related to the duration of time in which patients underwent haemodialysis approximately less than 6 month. This reflected that patients were still newly diagnosed with CKD or ESRD that required them to undergo haemodialysis. ${ }^{4}$

\section{Depression, anxiety and stress among patients with haemodialysis}

Low depression score was reported in patients underwent haemodialysis in the present study. This was contradictory to the results of previous study which found that most patients underwent haemodialysis had various degrees of depression from mild to severe. ${ }^{27}$ The possible explanation for low depression score of patients in the present study maybe due to the age of the patients who were mainly in the middle age group. Previous study reported that there was significant correlation between age and level of depression among patient with CKD. ${ }^{28}$ Another possible reason was majority of patients in the present study were employed and employment has been shown to have a negative relationship with level of depression. Other explanation for the low depression score was the relationship between duration of undergoing haemodialysis and depression. Patients who have a long term hemodialysis were significantly associated 


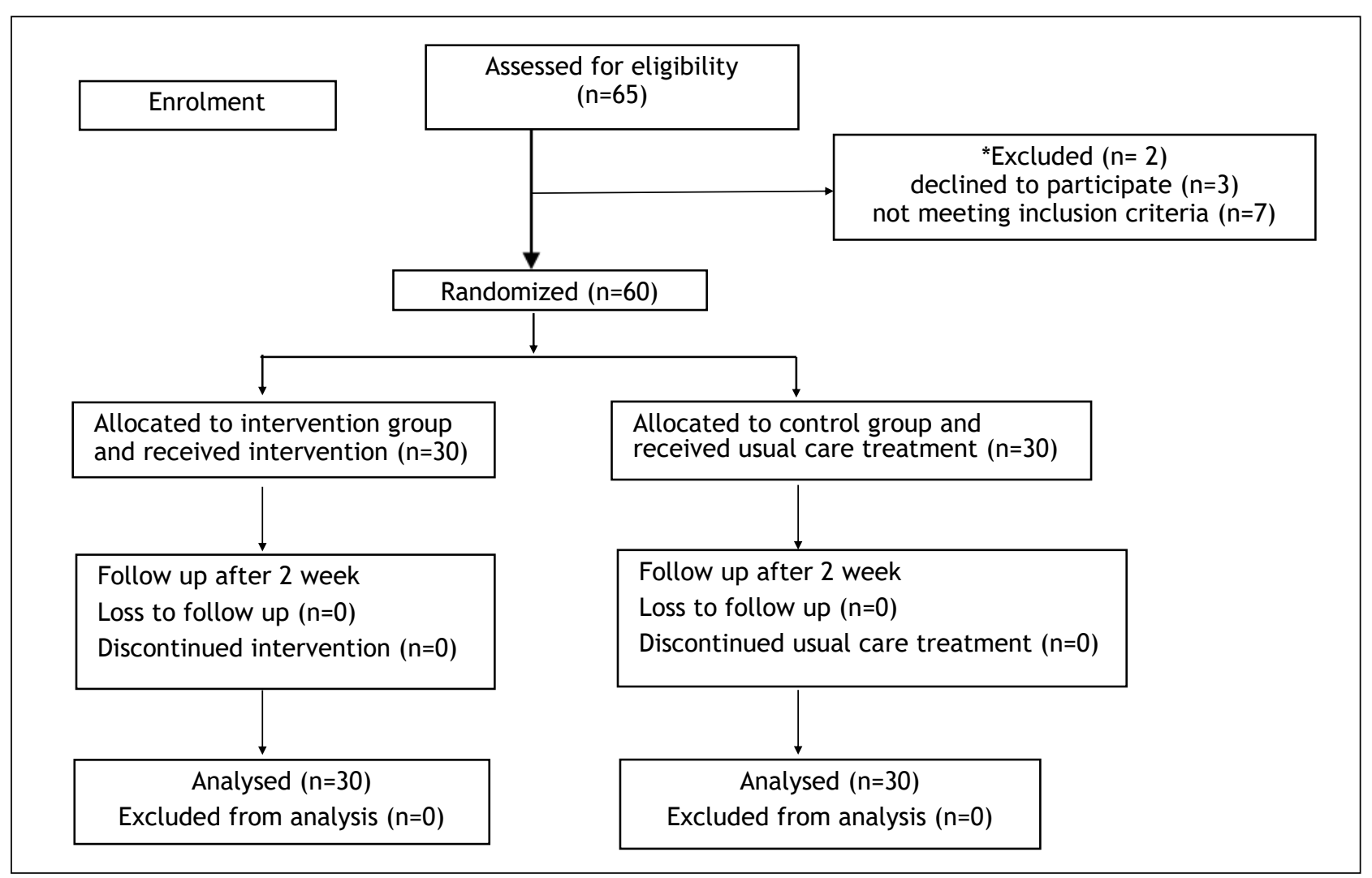

* 2 respondents were excluded due to unstable heamodynamic prior to randomization

Figure 1. Study flow chart

with depression ${ }^{29,30}$ and majority of patients in this study have undergone hemodialysis not exceeded than 6 months.

High level of stress and anxiety were reported in the present study and the result is similar to the one found by Bujang, et al. ${ }^{31}$ The authors found that almost $50 \%$ of dialysis patients have experienced anxiety and stress and the result was replicated in the study that conducted by Jahromi, et al., it was found that the mean scores of anxiety and stress of hemodialysis patients was 16 which reflected a moderate level of anxiety and stress. ${ }^{32}$ Anxiety and stress symptoms were found to be related by the uncertainty experienced by patients in reagrds to their disease progression and longterm care. ${ }^{31,32}$

\section{Effectiveness of PMR in depression, anxiety and stress}

The present study revealed that depression scores reduced significantly after PMR performed by patients in the study group but no change was found in the control group. The finding is supported by studies by $\mathrm{Ku}$, et al. and $\mathrm{Li}$, et al. ${ }^{9,33} \mathrm{Ku}$, et al. examined depression and quality of life in patients with chronic renal failure and polyneuropathy who were on haemodialysis and found that PMR was effective in lowering depression. ${ }^{9}$ PMR helped patients to achieve quick and easy state of relaxation that later assisted them to overcome depressive symptoms effectively. Another study also reported similar finding in which PMR significantly decreased mean depression score in the group which was given relaxation therapy, but not in the control group. ${ }^{33}$

Results from a meta-analysis also found that relaxation is more effective in reducing symptoms of depression and in cases of moderate to severe depression, relaxation intervention should be considered as complementary therapy in addition to antidepressants or other forms of psychological treatments. The study finding was also supported by results from Montazeri-Khadem, et al. ${ }^{34}$ Seyed, et al. ${ }^{20}$ and Heshmatifar, et al. ${ }^{12}$ PMR was also found to be effective in conditions other than patients undergoing haemodialysis but also in mothers after their caesarean surgery and primigravida women.

In regards to PMR effect on anxiety, the study found PMR is also effective in lowering anxiety symptoms among patients underwent haemodialysis. The 
present finding concurs with the studies by Rambod, et al. \& Heidarigorji, et al. and which investigated the impact of Benson relaxation training in hemodialysis patients on changes in perceived stress, anxiety, and depression. The result showed that mean scores of anxiety among respondents the intervention group decreased significantly. ${ }^{35,36}$ Previous studies also revelaed that PMR helped in improving anxiety and sleep quality among patients with haemodialysis ${ }^{17}$ and Cheung, et al. $^{15}$ who conducted study on 38 patients with haemodialysis who performed a PMR self-training program using video recording has found significant reduction in anxiety level as compared to the control group. In addition, PMR effect also significantly reduced anxiety levels in patients with breast cancer who received chemotherapy. ${ }^{19}$

The present study revealed the average stress score decreased significantly after being given progressive muscle relaxation therapy in the intervention group. In PMR, stress reduction mechanism occurs via changes in the sympathetic nervous system activity that decreased heart and respiratory work, increasing blood flow to large muscles and decreasing muscle tension that will inhibit the activation of stress hormones. ${ }^{37,38}$ Chronic stress has also been associated with decreased immune function which can be demeaning to one's physical health. ${ }^{39}$ Therefore, strategies to reduce stress and improve positive emotions may help to improve the body immune system that affects physical health. Positive health benefits on giving PMR have also been documented in hypertensive patients who report a decrease in blood pressure, pulse rate, perceived pressure, and overall health improvement. ${ }^{40}$

\section{CONCLUSION}

In conclusion, depression, anxiety and stress are identifed in patients who undergo haemodialysis and PMR is found to be effective in reducing the psychological symptoms. The clinical implication of the study would be to recommend screening of psychological symptoms among patients with CKD. PMR should also be recommended as the immediate form of psychological intervention while receiving haemodialysis as it helps in reducing depression, anxiety and stress.

However, the results of the study should be interpreted cautiously in the light of its limitations.
The quasi experimental study design has limitation on the true random allocation of the respondents and therefore may contribute to the selection bias. The blinding process is also limited as the process of masking the intervention was not possible. The sample size was still considered small although it was estimated based on the relevant parameters. In view of these limitations, future research is suggested to include multiple study locations and the study design would take into account the true randomization and blinding process.

\section{ACKNOWLEDGMENT}

The author received administrative support from the Director and nursing staff from the hemodialysis unit at Ir. Soekarno Hospital, Sukoharjo, Indonesia.

\section{REFERENCES}

1. NICE. Chronic kidney disease in adult: Assessment and Management [Internet]. 2014. Available from: nice.org.uk/guidance/cg182

2. Eckardt KU, Coresh J, Devuyst O, Johnson RJ, Köttgen A, Levey AS, et al. Evolving importance of kidney disease: From subspecialty to global health burden. Lancet. 2013;382(9887):158-69.

3. Registry IR. 8th Report Of Indonesian Renal Registry [Internet]. 2015. Available from: https://www.indonesianrenalregistry.org/ data/INDONESIAN RENAL REGISTRY 2015.pdf

4. Prodjosudjadi W, Suhardjono, Suwitra K, Pranawa, Widiana IGR, Loekman JS, et al. Detection and prevention of chronic kidney disease in Indonesia: Initial community screening. Nephrology. 2009;14(7):669-74.

5. Hill NR, Fatoba ST, Oke JL, Hirst JA, Lasserson CAODS, Hobbs FDR. Global Prevalence of Chronic Kidney Disease - A Systematic Review and Meta-Analysis. PLoS One. 2016;11(7):1-18.

6. Fauziyati A. Global challenge of early detection and management of chronic kidney disease. Indones J Med Heal. 2017;8(1):1-2.

7. Ibrahim K, Taboonpong S, Nilmanat K. Coping and Quality of Life among Indonesians Undergoing Hemodialysis. Thai J Nurs Res. 2009;13(2):109-17.

8. De Sousa A. Psychiatric issues in renal failure and dialysis. Indian J Nephrol [Internet]. 2008;18(2):47. Available from: http:// www.indianjnephrol.org/text.asp? 
$2008 / 18 / 2 / 47 / 42337$

9. Ku DY, Park YS, Chang HJ, Kim SR, Ryu JW, Kim WJ. Depression and life quality in chronic renal failure patients with polyneuropathy on hemodialysis. Ann Rehabil Med. 2012;36(5):702 $-7$.

10. Sagduyu A, Senturk V, Sezer S, et al. Psychiatric problems, life quality and compliance in patients treated with haemodialysis and renal transplantation Psychiatric Problems, Quality of Life , and Compliance in Patients Treated with Haemodialysis and Renal Transplantation. Turkish J Psychiatry. 2006;17(1):1-10.

11. Rabiei L, Eslami AA, Abedi HA, Masoudi R, Sharifirad GR. Caring in an atmosphere of uncertainty: perspectives and experiences of caregivers of peoples undergoing haemodialysis in Iran. Scand J Caring Sci. 2016;30(3):594-601.

12. Heshmatifar N, Sadeghi H, Mahdavi A, Shegarf Nahaee M RM. The Effect of Benson Relaxation Technique on Depression in Patients Undergoing Hemodialysis (Abstract). J Babol Univ Med Sci. 2015;17(8):34-40.

13. Bayat N, Alishiri G H, Salimzadeh A et al. Symptoms of anxiety and depression: A comparison among patients with different chronic conditions (Abstract). J Res Med Sci. 2011;16(11):441-7.

14. Kozier E. Fundamental Of Nursing: Concepts, Process and Practice. Pearson; 2011.

15. Cheung YL, A M, AM C. The effect of progressive muscle relaxation training on anxiety and quality of life after stoma surgery in colorectal cancer patients. Psychooncology [Internet]. 2003;12(3):254-66. Available from: http://www.embase.com/search/results? subaction=viewrecord\&from=export\&id=L36456 869\%5Cnhttp://dx.doi.org/10.1002/pon.638

16. Manzoni GM, Pagnini F, Castelnuovo G, Molinari1 E. Relaxation training for anxiety: a ten-years systematic review with metaanalysis. BMC Psychiatry. 2008;8(41):1-12.

17. Yildirim $Y$, Fadiloglu $C$. The effect of progressive muscle relaxation training on anxiety levels and quality of life in dialysis patients (Abstract). Edtna-Erca J. 2006;32 (2):86-8.

18. Essa RM, Ismail NIAA, Hassan NI. Effect of progressive muscle relaxation technique on stress, anxiety, and depression after hysterectomy. J Nurs Educ Pract [Internet].
2017;7(7):77. Available from: http:// www.sciedupress.com/journal/index.php/ jnep/article/view/9987

19. Yilmaz SG, Arslan S. Effects of progressive relaxation exercises on anxiety and comfort of Turkish breast cancer patients receiving chemotherapy. Asian Pacific J Cancer Prev. 2015;16(1):217-20.

20. Ahmadi S, Nejad F, Golmakani N, Shakeri M. Effect of Progressive Muscle Relaxation on depression, anxiety, and stress of primigravid women (Abstract). Evid based care. 2015;5 (1):67-76.

21. Zakerimoghadam M, Shaban M, Mehran A, S Hashemi. Effect of Muscle Relaxation on Anxiety of Patients Undergo Cardiac Catheterization (Abstract). J Hayat. 2010;16 (2):64-71.

22. Eriksen BO, Ingebretsen $\mathrm{OC}$. The progression of chronic kidney disease: A 10-year populationbased study of the effects of gender and age. Kidney Int. 2006;69(2):375-82.

23. Evans M, Fryzek JP, Elinder CG, Cohen SS, McLaughlin JK, Nyrén O, et al. The natural history of chronic renal failure: Results from an unselected, population-based, inception cohort in Sweden. Am J Kidney Dis. 2005;46(5):863-70.

24. Carrero JJ. Gender differences in chronic kidney disease: Underpinnings and therapeutic implications. Kidney Blood Press Res. 2010;33 (5):383-92.

25. Haroun M, Jaar B, Et AHS. Risk factors for chronic kidney disease: a prospective study of 23,534 men and women in Washington County, Maryland (Abstract). J Am Soc Nephrol. 2003;14:2934-2941.

26. Tan CE, Tohit N, Shah SA, Lee CC, Knowledge C. Chronic Kidney Disease Stage 3B among Malaysian Diabetics in Primary Care and its Associated Factors: A Pilot 5-Year Case Control Study Chronic Kidney Disease Stage 3B among Malaysian Diabetics in Primary Care and its Associated Factors: A Pilot 5-Year Case Control Study. 2013;(July 2014).

27. Cengic B, Resic H. Depression in Hemodilysis Patients. Bosn J Basic Med Sci. 2010;10(1):73-8.

28. Drayer RA, Piraino B, Reynolds CF, Houck PR, Mazumdar S, Bernardini J, et al. Characteristics of depression in hemodialysis patients: symptoms, quality of life and mortality risk. Gen Hosp Psychiatry. 2006;28(4):306-12. 
29. Farrokhi F, Abedi N, Beyene J, Kurdyak P, Jassal SV. Association between depression and mortality in patients receiving long-term dialysis: A systematic review and metaanalysis. Am J Kidney Dis [Internet]. 2014;63

(4):623-35. Available from: http:// dx.doi.org/10.1053/j.ajkd.2013.08.024

30. Shirazian S, Grant CD, Aina O, Mattana J, Khorassani F. Depression in Chronic Kidney Disease and End-Stage Renal Disease: Similarities and Differences in Diagnosis, Epidemiology, and Management. Kidney Int Reports [Internet]. 2017;2(1):94-107. Available from: http://dx.doi.org/10.1016/ j.ekir.2016.09.005

31. Bujang MA, Musa R, Liu WJ, Chew TF, Lim CTS, Morad Z. Depression, anxiety and stress among patients with dialysis and the association with quality of life. Asian J Psychiatr [Internet]. 2015;18:49-52. Available from: http:// dx.doi.org/10.1016/j.ajp.2015.10.004

32. Kargar Jahromi M, Javadpour S, Taheri L, Poorgholami F. Effect of Nurse-Led Telephone Follow ups (Tele-Nursing) on Depression, Anxiety and Stress in Hemodialysis Patients. Glob J Health Sci [Internet]. 2015;8(3):168. Available from: http://www.ccsenet.org/ journal/index.php/gjhs/article/view/47975

33. Li Y, Wang R, Tang J, Chen C, Tan L, Wu Z, et al. Progressive muscle relaxation improves anxiety and depression of pulmonary arterial hypertension patients. Evidence-based Complement Altern Med [Internet]. 2015;2015:792895. Available from: http:// www.embase.com/search/results? subaction=viewrecord\&from $=$ export\&id $=\mathrm{L} 60383$ 3998\%5Cnhttp:// dx.doi.org/10.1155/2015/792895\%5Cnhttp:// resolver.ebscohost.com/openurl? sid=EMBASE\&issn=17414288\&id=doi: $10.1155 \%$ 2F2015\% 2F792895\&atitle $=$ Progressive + muscle + relaxat

34. Khadem VM-, Mohammadi RS. The effectiveness of stress management on volunteer mothers ' anxiety and depression to cesarean surgery. Int J Pschchology Behav Res. 2014;1(4):567-71.

35. Rambod M, Sharif F, Pourali-Mohammadi N, Pasyar N, Rafii F. Evaluation of the effect of Benson's relaxation technique on pain and quality of life of haemodialysis patients: A randomized controlled trial. Int J Nurs Stud
[Internet]. 2014;51(7):964-73. Available from: http://dx.doi.org/10.1016/

j.ijnurstu.2013.11.004

36. Heidarigorji A, Heidari Gorji M, Davanloo Aa. The efficacy of relaxation training on stress, anxiety, and pain perception in hemodialysis patients. Indian J Nephrol [Internet]. 2014;24 (6):356. Available from: http:// www.indianjnephrol.org/text.asp? 2014/24/6/356/132998

37. Hui PN, Wan M, Chan WK, Yung PMB. An Evaluation of Two Behavioral Rehabilitation Programs, Qigong Versus Progressive Relaxation, in Improving the Quality of Life in Cardiac Patients. J Altern Complement Med [Internet]. 2006;12(4):373-8. Available from: http://www.liebertonline.com/doi/ abs/10.1089/acm.2006.12.373

38. Freeman L. Meditation: Complementary and Alternative Medicine: A Research-Based Approach. 3rd ed. Louis: S, editor. Mosby Elsevier; 2009.

39. Denson TF, Spanovic M, Miller N. Cognitive Appraisals and Emotions Predict Cortisol and Immune Responses: A Meta-Analysis of Acute Laboratory Social Stressors and Emotion Inductions. Psychol Bull. 2009;135(6):823-53.

40. Sheu S, Irvin B, Lin H, Mar C. The effects of progressive muscle relaxation on blood pressure and psychosocial status for clients with essential hypertension in Taiwan (Abstract). Holist Nurs Pract. 2003;17(1):41-7. 